\title{
Effects of Observation on the Psychotherapeutic Process Revisited: Brief Report
}

\author{
Jack Demick ${ }^{1 *}$ and Casey Marks ${ }^{2}$
}

${ }^{1}$ Department of Psychology, Harvard University, Cambridge, Massachusetts 02138, USA

${ }^{2}$ Professional Programs at (ISC) ${ }^{2}$, Clearwater, Florida, USA

\begin{abstract}
With the advent of one-way mirrors, videotapes, smartphones with filming capabilities, and other audio-visual devices, much research has been conducted on the effects of observation on the psychotherapeutic process However, as outlined by Zinberg, this research has traditionally focused on the ways in which observation affects isolated processes in both therapists (e.g., concentration) and patients (e.g., defense mechanisms) or simply on participants' (patients, trainees)experience of observation with both sets of participants reporting favorable attitudes. In contrast, the present work describes a case study in which the in vivo non-participant observation of an ongoing therapy case led to extremely positive therapeutic benefits for the patient. Underlying processes (e.g., life review, mindfulness, self-other differentiation) and mechanisms (e.g., activation of self- and relational observation, elaboration of affect-laden material) as well as implications for therapy, education, and research are discussed.
\end{abstract}

Keywords: Medical education; One-way mirrors; Videotaping; Nonparticipant observation activation of self- and relational observation; Life review; Self - other differentiation

Although videotapes, one-way mirrors, smartphones with filming capabilities, and other audio-visual devices have recently become more common than in vivo non-participant observation in psychotherapy teaching and practice, researchers have generally agreed that, regardless of the particular format, "the introduction of a third person (and fourth and fifth persons) into the psychotherapeutic setting markedly changes the quality of the experience both for the patient and the therapist" [1]. Despite this agreement, however, surprisingly little research has been conducted on the effects of observation on the therapeutic process. Part of this has been related to ethical concerns, for example, ongoing questions concerning personal and social boundaries breached by such observations $[2,3]$, while part has been tied to methodological considerations, for example, managing the complexity of variables inherent in both "private" and public interviews [4]. Research on each is briefly summarized below.

First, researchers $[5,6]$ have generally concluded that patients, therapists, and observers would all encounter fewer difficulties (e.g., less stress concerning identities and reactions of observers) were observers literally to sit in treatment rooms. In line with this, Ziferstein [7] has documented that Russian psychiatrists typically allow observers in the room on the perhaps collectivist assumption that such direct observation leads to less disturbing effects on the process than do more elaborate precautions.

Second, empirical research on the effects of observation on the therapeutic process has traditionally focused on the ways in which observation affects isolated variables in therapists (e.g., lack of concentration), patients (e.g., heightened use of defense mechanisms), and/or therapeutic contexts (e.g., lack of suspension of usual social rules as obtain in psychotherapy). A second strand of relevant research has limited itself to the assessment of participants' experience of an observation with predominantly favorable feelings reported by both patients [8] and trainees [9]. However, given the complexity of variables involved in psychotherapy and its observation, relatively few if any studies have attempted to assess, in a more in-depth and/ or comprehensive manner, the potential positive therapeutic benefits of observations on patients. Even though non-participant observation has a long and variegated history within the teaching and practice of psychotherapy [10], the present study begins to fill this gap.

\section{Rationale for the Present Study}

Several years ago, one of the authors served as a small group leader for the introductory psychiatry course, The Brain and Human Behavior, offered to medical students through the Warren Alpert Medical School of Brown University. Each week, the author and/or a medical student interviewed a different patient from the author's psychotherapy caseload while other students within the room observed the interaction. Somewhat surprisingly, numerous patients with a variety of diagnoses (e.g., Asperger's Disorder, Bipolar Disorder, Major Depressive Disorder, Schizophrenia) volunteered to be interviewed. Following the interviews, patient feedback was uniformly positive with the majority noting that talking with students both decreased affect associated with negative experience (e.g., "I realized I could talk about myself and it wasn't so bad") and/or improved their self-esteem (e.g., "It felt good helping teach students about my disorder"); several even commented that students' reactions and questions were helpful to them (e.g., "It made me think about myself in a new way").

Thus, when approached the following year by two undergraduate psychology majors to offer an independent study course on psychotherapy (in which they proposed to observe one weekly therapy case over the course of a number of weeks), patients were again polled and many, most of whom had participated in the previous psychiatry course, volunteered for the opportunity. One was selected for this process. The decision to select the particular patient was based on the

*Corresponding author: Jack Demick, Fellow, Department of Psychology, Harvard University, Cambridge, Massachusetts 02138, USA, Tel: (617) 495-4024; E-mail: jack_demick@harvard.edu

Received September 03, 2016; Accepted September 22, 2016; Published September 28, 2016

Citation: Demick J, Marks C (2016) Effects of Observation on the Psychotherapeutic Process Revisited: Brief Report. J Ment Disord Treat 2: 124. doi:10.4172/2471271X.1000124

Copyright: ( 2016 Demick J, et al. This is an open-access article distributed under the terms of the Creative Commons Attribution License, which permits unrestricted use, distribution, and reproduction in any medium, provided the original author and source are credited. 
facts that the therapy was ongoing (every week with no absences) and long-term (the patient had been in therapy for 4 years and was both extremely verbal and relatively stable).

\section{Method}

\section{Design and procedure}

The students and patient each met individually with one of the authors to discuss ethical concerns (e.g., confidentiality) and logistics. It was mutually agreed that the students would attend weekly sessions over a 2-month period and function as non-participant observers [11] sitting behind the therapist and patient (8 sessions).

\section{Results}

\section{Brief patient background}

Ms. X was a 55-year-old married Caucasian woman with a history of major depression and problems with appetitive behaviors such as binge eating and gambling. She had a 27 -year-old daughter from a first short-lived marriage (at age 16 years), which she claimed was simply to allow her to leave her abusive mother and brothers (e.g., as a child, Ms. X was allegedly diagnosed with Munchausen's Syndrome by Proxy). Although her daughter recently suffered from cancer, Ms. $\mathrm{X}$ and she were, at the beginning of the observation, estranged because daughter felt as if Ms. X did not wish to get better. Related to a host of medical concerns (some legitimate, others less so), Ms. X was currently unemployed and claimed that she could not find employment.

\section{Psychotherapy process}

Although attempts were made to have the observers be as unobtrusive as possible, Ms. X could not ignore their presence and often directed her comments to them. Over the course of the 8 weeks, she became more inquisitive about them (e.g., bringing them small treats, offering to drive them home after the session). At the end of the 8-week session, she even invited them to continue observing her sessions over the summer.

\section{Outcome}

Prior to the observation, Ms. X had been seen in weekly psychotherapy for 4 years. While she had gained some insight into her functioning, she often resisted interpretations and still switched from one problematic behavior (e.g., binge eating) to another (e.g., gambling). Arguably the therapy was at an impasse. However, after the observation, this appeared no longer the case. Seemingly related to the observers' presence, several notable developments occurred.

- Ms. X felt the need to provide a systematic review of her symptoms beginning in childhood. Over the course of her recounting close to 50 years of physical problems, she finally emoted: "My husband and my daughter tell me I have Munchausen's Syndrome... Oh my god, I do!"

- When the observers did not reciprocate Ms. X's kindnesses, she had the major insight that historically she had been nice to others, in an almost manipulative manner, so that they might like her.

- Perhaps related to the observers' non-reciprocal stance, Ms. $\mathrm{X}$ instead turned toward and ultimately reconnected with her daughter.

- Perhaps as a way of pleasing the observers and/or as a function of feeling better about herself (e.g., educating others), Ms. X was finally able to procure employment (sales clerk in dollar store) and is currently working on a manuscript about her life that she is hoping to publish.

\section{Discussion}

The present case study suggests that the presence of an observer or observers has the potential to lead to positive therapeutic benefits for at least some patients. Continued research and verification is required to determine if this holds for all patients and whether there are factors predictive of its success (e.g., diagnosis, length of prior treatment, therapist characteristics, cultural context).

How does the presence of an observer or observers lead to positive therapeutic benefits? First, the patient may, consciously or unconsciously, feel a need to review his or her history for the benefit of the observer and in doing so might rework through difficult material that he or she had been avoiding and/or gain fresh insights informed by his or her previous work in therapy. In some ways, this process was reminiscent of the "life review" of older adults, described by Butler, Lewis, and Sunderland [12] as the "natural healing process" of examining one's own life and one's role in the history of human life. In other ways, the need to review one's history also offers the patient an opportunity to elaborate and work through - perhaps for a second or third time - difficult affect-laden material.

Second, the presence of an observer may force the patient to deal with the "generalized other" whose presence in the treatment room is most usually discussed but not necessarily experienced firsthand. In other words, the presence of an observer may help activate the related processes of self- and relational observation [13]. According to Horowitz [14], self- and relational observation-which consists of the awareness of feelings/ideas/emotional control, changing states of mind, and self-concepts or schemas including mental models of roles in a relationship - can be brought about through mindfulness. As defined by Langer [15], mindfulness is "the simple act of noticing new things," a state that might easily be brought about by the literal introduction of observers into one's psychotherapy.

Third, the presence of an observer may also allow the therapist to deal more effectively with transference indirectly. For example, when our non-participant observers maintained their non-reciprocal stance, for example, refusing the patient's offers to drive them home and to extend the predetermined period of observation, she appeared to become angry and disappointed although she did not express these sentiments to them.

However, the observers' non-reciprocal stance allowed her to have insights about the nature of her relationships, appropriately to reconcile instead with her daughter through honesty and acts of kindness, and ultimately to return to therapy following the end of the observation period to discuss her feelings - both positive and negative-about her therapist, which she had not done in as honest a manner previously.

Finally, the introduction of non-participant observers into the psychotherapeutic process is consistent with the second author's academic work on holistic/systems-developmental theory [16], which is an elaboration and extension of Werner's [17] organismicdevelopmental theory. In the former, the person-in-environment is the unit of analysis with mutually defining aspects of persons (physical, intra-personal, sociocultural) and of environment (physical, interpersonal, sociocultural). Thus, given the transactional nature of the person-in-environment system (in which the person and his or her environment cannot be separated since they mutually define one 
Citation: Demick J, Marks C (2016) Effects of Observation on the Psychotherapeutic Process Revisited: Brief Report. J Ment Disord Treat 2: 124. doi:10.4172/2471-271X.1000124

Page 3 of 3

another), the introduction of observers into therapy in some ways makes the psychotherapeutic process more ecologically valid.

In addition, the introduction of observer's potentially allows the patient to work through issues around self-other differentiation, a central theme within Wernerian theory and its extensions. Although non-participant observers enter the therapy system and become part of it, it is important for patients to understand that they do not become fused with the observer(s) but rather that they collectively as individuals mutually define the therapeutic system in the time and space in which the therapy occurs. It is noteworthy that this approach shares some similarities to Ziferstein's [5,7] description of the features and practices (e.g., informality, availability, activity) of psychiatrists in the former Soviet Union, which reflect their place in a collectivist society. Similar to the person-in-environment as unit of analysis, the unit of analysis in Soviet psychiatry appears to be the person-in-society, leading to the more specific units of analysis of psychiatrist-in-society, psychotherapist-in-society, and patient-in-society. This parallels the leading Soviet developmental psychologist, Vygotsky's [18] notion that psychological processes are not innate but develop through the person's active relationship with the social environment. Specifically, his concept of the "zone of proximal development" (the distance between the child's actual developmental level as determined by independent problem solving and the level of potential development as determined through problem solving under adult guidance or in collaboration with more capable peers) implies too that the unit of analysis in Soviet developmental psychology is the child-in-society.

The above empirical and theoretical notionsare clearly worthy of further inquiry as they have implications for the practice, teaching, and research of psychotherapy. Further, research on the effects of observation on the psychotherapeutic process would do well to develop global and specific measures of therapeutic benefit to be completed in an ongoing manner (e.g., prior to and/or following each observation) not only by the patient but also by his or her therapist and observer(s) as well.

\section{References}

1. Carmichael HT (1966) Sound-film recording of psychoanalytic therapy: A therapist's experiences and reactions. In: Gottschalk LA, Auerbach AH (eds.) Methods in research in psychotherapy, New York: Appleton-Century-Crofts.
2. Funkenstein $A B$, Kessler KA, Schen $C R$ (2014) Learning through the lens: Ethical considerations in videotaping psychotherapy. Harvard Review of Psychiatry 22: 316-322.

3. Schuster EA (1976) Privacy, the patient and hospitalization. Social Science Medicine 10: 245-248.

4. Abbass A (2004) Small-group videotape training for psychotherapy skills development. Academic Psychiatry 28: 151-155.

5. Ziferstein I (1966) The Soviet psychiatrist: His relationship to his patients and to his society. American Journal of Psychiatry 123: 440-446.

6. Zinberg NE (1985) The private versus the public psychiatric interview. American Journal of Psychiatry 142: 889-894.

7. Ziferstein I (1971) Effects of observation on the therapeutic process. American Journal of Psychiatry 128: 353-356.

8. Burgoyne RW (1978) Observed psychotherapy: What the patients say about it Journal of Psychiatric Education 2: 83-92.

9. Nelson GL (1978) Psychotherapy supervision from the trainee's point of view: A survey of preferences. Professional Psychology 9: 539-550.

10. Freud S (1963) Recommendations to physicians practicing psychoanalysis Introductory lectures on psychoanalysis: Complete psychological works. London: Hogarth Press.

11. Berg BL (2006) Qualitative research methods for the social sciences. (6thedn) Boston: Allyn and Bacon.

12. Butler RN, Lewis MI, Sutherland T (1998) Aging and mental health: Positive psychosocial and biomedical approaches. (5thedn) Boston: Allyn \& Bacon.

13. Beitman BD, Sothm AM (2006) Activation of self-observation: A core process among the psychotherapies. Journal of Psychotherapy Integration 16: 383-397.

14. Horowitz MJ (2002) Self- and relational observation. Journal of Psychotherapy Integration 12: 115-127.

15. Langer EJ (1989) Mindfulness. Reading, MA: Addison-Wesley.

16. Demick J (2016) Changing the face of parent development: Holistic/systems developmental therapy for parents. In: Kirkcaldy BD (ed.) Personal enrichment in our lives: Psychotherapy in parenthood andbeyond. Torino, Italy: Edizioni Minerva Medica.

17. Werner H (1957) Comparative psychology of mental development. New York: International Universities Press.

18. Vygotsky LS (1978) Mind in society: The development of higher psychological processes. Cambridge, MA: Harvard University Press. 